\title{
12 Understanding the Enzymatic Degradation of Biodegradable Polymers and Strategies to Control Their Degradation Rate
}

\author{
Helena S. Azevedo and Rui L. Reis
}

\section{CONTENTS}

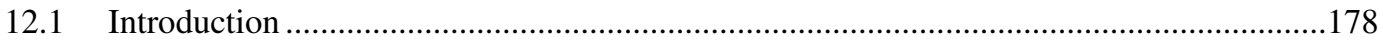

12.2 Importance of Biodegradability in Biomedical Applications...........................................178

12.3 Degradation Processes in Biodegradable Polymers ……………......................................179

12.3.1 Chemical and Enzymatic Oxidation...............................................................180

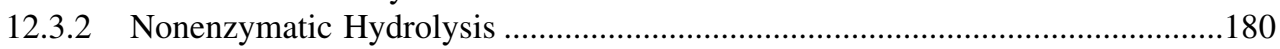

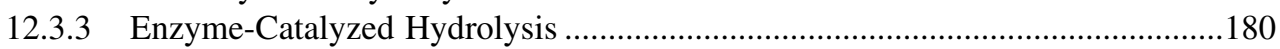

12.3.3.1 Factors Affecting Enzymatic Hydrolysis............................................181

12.3.3.2 Potential Enzymes Involved in the Degradation of Biodegradable Polymers, Their Activities, and Half-Lives in Human Plasma..........182

12.4 In Vitro Studies to Assess the Degradation Kinetics of Biodegradable Polymers ............184

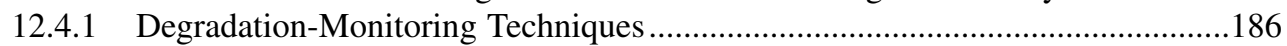

12.4.1.1 Water Absorption and Weight Loss.................................................187

12.4.1.2 Molecular Weight...........................................................................187

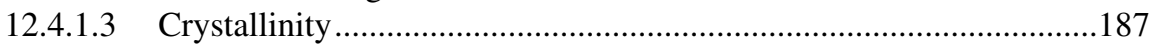

12.4.1.4 Morphology and Dimensional Changes ............................................188

12.4.1.5 Surface Chemistry ………............................................................188

12.4.1.6 Mechanical Properties........................................................................189

12.4.1.7 Isolation and Identification of Degradation Products .........................189

12.4.2 Mechanisms of Degradation............................................................................190

12.4.3 Strategies for Controlling the Degradation Rate of Biodegradable

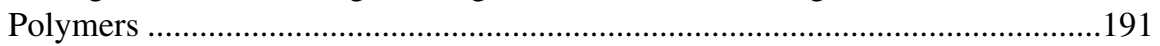

12.5 Enzymatic Degradation of Starch-Based Biomaterials - A Case in Study .....................192

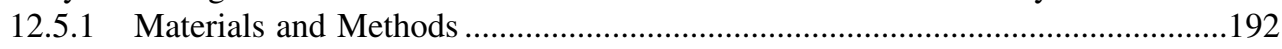

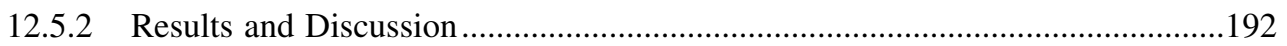

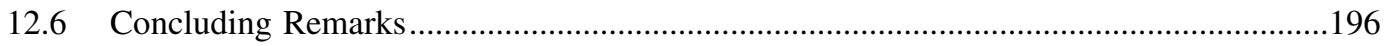

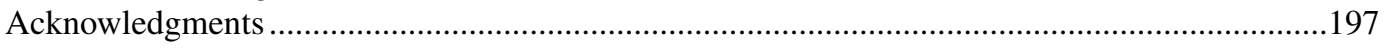

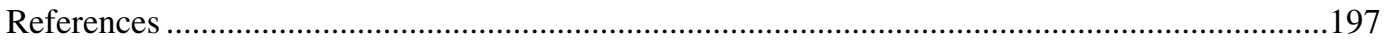




\subsection{INTRODUCTION}

Nature has always provided, in considerable amounts and variety, polymeric materials with interesting compositions and structures and with great potential to be used in biomedical applications. These natural polymers include polysaccharides, ${ }^{1}$ such as cellulose, chitin, starch, alginate, galactan, hyaluronic acid, dextran, and gellan, obtained from plants, animals, and microbial sources and polyesters, ${ }^{2}$ such as poly( $\beta$-hydroxybutyrate) and poly( $\beta$-hydroxybutyrate-co- $\beta$-hydroxyvalerate), produced by numerous bacteria. In biological systems, polysaccharides and their derivatives are found as energy reservoirs, as components of the cell wall of plants, in bacteria, and in the connective tissues. ${ }^{3,4}$

Since the early 1960s, several synthetic degradable polymer systems have been used as medical implant materials, ${ }^{5}$ which include various polyesters, polyurethanes, polyanhydrides, polyacrylates, polyphosphoesters, and polydiaxanone, among others. ${ }^{3,6}$ Over decades of research, many new biomaterials have been developed, but the prospect for novel biomaterials and novel applications continues to be immense.

Applications of biodegradable polymers in medicine (please see Chapter 1 by Suzuki and Ikada in this book) include resorbable surgical sutures, matrices for the controlled release of drugs, scaffolds for tissue engineering, and resorbable orthopedic devices such as bone cements, pins, screws, and plates. ${ }^{7}$ The development of biomaterials requires an extensive evaluation, in terms of biocompatibility, mechanical properties, and degradation behavior, in order to determine whether a certain material is suitable for a particular application. Understanding the factors that control the degradation of biomaterials is, therefore, critical for the development of degradable polymeric systems, and a greater comprehension of these mechanisms would be helpful to optimize their current usage. The demand for biomaterials with controlled, predictable degradation kinetics includes a wide range of biomedical applications, and this had led to extensive research on the degradation behavior of a variety of biodegradable polymers. Great attention has been devoted to the study of degradation mechanisms of poly(lactic acid)-based polymeric systems, and a vast literature (research articles ${ }^{8-15}$ and reviews ${ }^{6,16}$ ) is now available.

This chapter intends to provide the reader with an overview on the degradation mechanisms of biodegradable polymers with special emphasis on the main parameters affecting the enzymatic degradation of polymeric biomaterials. For that, a range of potential enzymes involved in the degradation of polymeric biomaterials will be considered, taking into account their normal levels in the human body fluids and their secretion during inflammatory responses. Some guidelines will be given for designing in vitro degradation studies, including a detailed description of the main characterization techniques that should be used to evaluate the degradation behavior of biomaterials under specific conditions. At the end of the chapter, a practical study about the enzymatic degradation of starch-based polymers will be presented and discussed, as well as a case study that was aimed to assess the degradation behavior of starch-based polymeric biomaterials under the influence of certain enzyme activities. In addition, the effect of $\alpha$-amylase encapsulation in starch-based matrices on their degradation profile was studied and will be presented herein with the perspective of developing biomaterials with enzymatically controlled degradation rates.

\subsection{IMPORTANCE OF BIODEGRADABILITY IN BIOMEDICAL APPLICATIONS}

The term biodegradation is often used to denote degradation occurring in a biological environment. In the context of biomedical applications, biodegradation may be defined as the "gradual breakdown of a material mediated by a specific biological activity."17

The performance of medical devices depends largely on the stability of the material, and biodegradation is a key issue on the list of safety standards when choosing materials for biomedical applications. 
Biodegradable polymers are materials with the ability to function for a temporary period and subsequently degrade, under a controlled mechanism, into products easily eliminated in the body's metabolic pathways. In this way, biodegradability not only eliminates the risk of complications associated with the long-term presence of a foreign material and the need for a second surgery for implant removal, but also allows for improved healing, as viable tissue interacts and grows into the degrading construct.

The use of polymeric materials in drug delivery applications also requires that the polymer degrade under physiological conditions and slowly release the encapsulated drug. The polymer should demonstrate, therefore, a continuous mass loss profile to facilitate repeated dosing and to ensure the successful effect of the treatments.

The degradation of biomaterials is also important in terms of biocompatibility, since the changes that occur in the physicochemical properties of the materials during degradation may alter their functionality and the associated biological response. In addition, the nature of the degradation products will, in part, define the ultimate biocompatibility of the materials since it may also induce alterations to cellular function.

Understanding the degradation mechanisms of biomaterials (degradation kinetics, evolution of mechanical properties, identification of degradation products) is, therefore, of crucial importance when selecting and designing materials for specific applications since the degradation process may affect a range of events such as cell growth, tissue regeneration, drug release, host response, and the material function.

\subsection{DEGRADATION PROCESSES IN BIODEGRADABLE POLYMERS}

The degradation of a biomaterial can occur at different stages of its preparation, including during its storage. For instance, it was observed that the molecular weight of poly $(L$-lactide $)$ decreased from 431,000 to 202,000 Da upon storage. ${ }^{8}$

The conditions used during the processing and fabrication of polymeric materials may also lead to polymer degradation, consequently influencing their degradation behavior in vivo. Meltbased techniques (injection molding, extrusion, compression molding) are performed at high temperatures and in the first two cases at high shear rates, which may cause some degradation of the material. The production of samples by injection molding leads to a partial material orientation, which is typically higher in the skin than in the core of the molding. The chain orientation across the sample upon processing may be responsible for a faster degradation in the center than in the skin. ${ }^{8}$ In addition, it is very common to use additives (plasticizers, lubricants, antioxidants, salts, stabilizers) during the processing of polymeric materials, which will leach out after immersion and may enhance or inhibit the degradation process.

Another aspect to be considered is the fact that biomedical materials need sterilization before being implanted. Sterilization can be performed using heat, steam, gas (ethylene oxide, EtO), or ionizing radiation, mainly $\gamma$ or $\beta$. Each of these sterilization methods may have an effect on the material degradation, but sterilization by radiation requires high doses of high-energy radiation, resulting in some cases in polymer crosslinking and degradation. $\gamma$ sterilization was shown to reduce significantly the molecular weight of poly(lactide-glycolide) polymers, ${ }^{6}$ but cold-cycle EtOH sterilization did not cause any changes in the molecular weight of polylactides. ${ }^{8}$ Mechanical stress may also affect the degradation, either as a result of loading under service or due to residual stress arising during manufacturing, but this type of degradation is more significant on materials subjected to mechanical stress such as sutures, scaffolds for tissue engineering, and fixation devices. ${ }^{6}$

Materials exposed to the body fluids may undergo changes in their physicochemical properties as a result of chemical, physical, mechanical, and biological interactions between the material and the surrounding environment. Although materials can be degraded by thermal and mechanical processes, only degradation by oxidation and hydrolysis will be discussed in more detail in the following sections of the present chapter. 


\subsubsection{Chemical and Enzymatic Oxidation}

Polymeric biomaterials may be degraded by chemical and enzymatic oxidation when exposed to the body fluids and tissues. It is well known that during inflammatory response to foreign materials, inflammatory cells, particularly leukocytes and macrophages, are able to produce highly reactive oxygen species such as superoxide $\left(\mathrm{O}_{2}^{-}\right)$, hydrogen peroxide $\left(\mathrm{H}_{2} \mathrm{O}_{2}\right)$, nitric oxide (NO), and hypochlorous acid $(\mathrm{HOCl}) .{ }^{17-19}$ The oxidative effect of these species may cause polymer chain scission and contribute to their degradation.

Several studies have been carried out to assess the effect of oxygen species in the degradation of polymeric biomaterials. ${ }^{17,19,20}$ Lee and $\mathrm{Chu}^{20}$ studied the role of superoxide in the degradation of absorbable sutures and found that $\mathrm{O}_{2}^{-}$could accelerate the degradation of aliphatic polyesters by the cleavage of ester bonds via nucleophilic attack of $\mathrm{O}_{2}^{-}$.

The effect of oxidative enzymes, such as horseradish peroxidase, catalase, and xanthine oxidase, on the degradation of poly(urethane)s (PUs) was also studied, but these oxidative systems were unable to induce degradation of PUs. ${ }^{21,22}$

A more detailed description about how oxidative enzymes, free radicals, superoxides, and peroxides influence the degradation of biomedical polymers can be found in a review by Williams and Zhong. ${ }^{17}$

\subsubsection{Nonenzymatic Hydrolysis}

Polymer hydrolytic degradation may be defined as the scission of chemical bonds in the polymer backbone by the attack of water to form oligomers and finally monomers. In the first step, water contacts the water-labile bond, by either direct access to the polymer surface or by imbibition into the polymer matrix followed by bond hydrolysis. Hydrolysis reactions may be catalyzed by acids, bases, salts, or enzymes. ${ }^{17}$

After implantation, the biomaterial absorbs water and swells, and degradation will progress from the exterior of the material toward its interior.

The hydrophilic and hydrophobic nature of polymeric materials influences their degradation rate, and the susceptibility to hydrolysis follows this order ${ }^{17}$ : (1) hydrophilic with hydrolysable bonds, (2) hydrophobic with hydrolysable bonds, (3) hydrophilic with no hydrolysable bonds, and (4) hydrophobic with no hydrolysable bonds. For instances, $N$-vinylpyrrolidinone (NVP) is capable of absorbing relatively large amounts of water, but it is not prone to hydrolysis. ${ }^{23}$

All biodegradable polymers contain hydrolysable bonds, such as glycosides, esters, orthoesters, anhydrides, carbonates, amides, urethanes, ureas, etc. ${ }^{3,6,17}$ Polymers with strong covalent bonds in the backbone (like C-C) and with no hydrolysable groups require longer times to degrade.,24

\subsubsection{Enzyme-Catalyzed Hydrolysis}

Enzymes are biological catalysts, i.e., they accelerate the reaction rates in living organisms without undergoing themselves any permanent change. In fact, in the absence of enzymes, most of the reactions of cellular metabolism would not occur. Hydrolysis reactions may be catalyzed by enzymes known as hydrolases, which include proteases, esterases, glycosidases, and phosphatases, among others. This class of enzymes comprises cell-derived proteins that are responsible for the catalysis of several reactions in the human body. For example, hydrolytic enzymes are present in the plasma and interstitium, in the brush border membrane and lumen of the gastrointestinal tract, and in the tubular epithelium of the kidneys, where they ensure the efficient hydrolysis of different substrates to facilitate absorption of nutrients and solutes. ${ }^{4}$

In this sense, it is expected that some of these enzymes may play an important role in the degradation of biomaterials by catalyzing their hydrolysis. It has been shown that the degree of biodegradation of polyurethanes, in the presence of cholesterol esterase enzyme, is about 10 times 
higher than in the presence of buffer alone. ${ }^{21}$ This fact may explain the higher in vivo degradation rates of some biomaterials when compared with in vitro experiments.

While some enzymes catalyze only one reaction involving only certain substrates, others are not very specific. This indicates that the degradation of synthetic polymers may also occur by enzymatic hydrolysis, and some examples of this will be given in Section 12.3.3.2.

\subsubsection{Factors Affecting Enzymatic Hydrolysis}

The enzymatic hydrolysis of polymeric biomaterials is a heterogeneous process that is affected by the mode of interaction between the enzymes and the polymeric chains and involves typically four steps $^{25}$ : (1) diffusion of the enzyme from the bulk solution to the solid surface, (2) adsorption of the enzyme on the substrate, resulting in the formation of the enzyme-substrate complex, (3) catalysis of the hydrolysis reaction, and (4) diffusion of the soluble degradation products from the solid substrate to the solution. The rate of the global reaction is controlled by the slowest step.

The adsorption and rate of hydrolysis reaction is affected by the physicochemical properties of the substrate (molecular weight, chemical composition, crystallinity, surface area) and also by the inherent characteristics of a specific enzyme (activity, stability, local concentration, amino acid composition, and 3-D conformation). It is also very important to take into account the medium conditions such as $\mathrm{pH}$ and temperature, since they influence both the properties of the substrate and of the enzyme. The presence of stabilizers, activators, or inhibitory products in the medium, resulting from material degradation or leaching out of processing additives, may affect the enzymecatalyzed reactions by influencing enzyme adsorption and activity.

The enzymatic hydrolysis of solid substrates is normally characterized by an enzyme saturation point; at this enzyme concentration, no further increase in the degradation rate is observed when more enzyme is added. This has been attributed to a decrease in the exposed polymer surface as the enzyme molecules saturate the surface and appears to be limiting the progress of degradation of some biomaterials. Such behavior was not observed by Tang et al., ${ }^{26}$ who studied the effect of enzyme concentration (cholesterol esterase, CE) on the degradation rate of polycarbonate polyurethanes (PCNUs). These authors found that the degradation of PCNUs was highly dependent on enzyme dose, and the dose response was influenced by the surface chemistry and structure of the polymer.

The chemical modification of polymers (crosslinking, removal, or introduction of chemical groups in the polymer chain) also affects the enzymatic degradation rates since, depending on the degree of chemical modification, it may compromise the ability of the enzyme to recognize the modified substrate. This seems to be the case of lysozyme (enzyme responsible for the degradation of peptidoglycan and also chitin materials), which exhibited low activity toward chitosans with high degrees of deacetylation ${ }^{27,28}$ or crosslinked chitosan. ${ }^{29}$

It was shown that different hard segment distributions at the surfaces of polyether-urea-urethanes could influence the manner in which the enzyme cholesterol esterase adsorbs, binds, and expresses its activity on the surface of the polymers. ${ }^{30-32}$ It was found, for instance, that as hard segment increased, the enzyme hydrolytic activity was reduced. ${ }^{32}$

The complex chemical nature of body fluids and inflamed tissues around the implant, the variability in the polymer material, and the variability associated with biological systems (e.g., rate of metabolism of the host) make the overall degradation of biomaterials a rather complicated process. The first interaction of an implanted biomaterial with the host tissue is the adsorption of proteins. The subsequent interactions are determined by the nature of the proteins adsorbed. Blood plasma contains over 150 proteins, and any of these may adsorb to the biomaterial, depending on the binding potential of the particular protein. ${ }^{33}$ Proteins may adsorb to a biomaterial surface with low affinity and may be replaced by other proteins with higher binding affinities. The deposition of proteins on the surface of biomaterials is followed by adherence of certain type of cells. 
The adsorption of other proteins to the polymer surface may influence the enzymatic degradation of biomaterials. It was shown, for example, that the preadsorption of fibrinogen (Fg) onto the modified and nonmodified surfaces of poly(ether-urethane) (PEU) polymers provided a temporary protective effect against the hydrolytic action of cholesterol esterase (CE) enzyme. ${ }^{34}$ This effect may be explained by the fact that the prior adsorption of $\mathrm{Fg}$ on the polymer surface might have occupied sites for CE adsorption, consequently limiting the access of the enzyme to the susceptible hydrolysable bonds. Another explanation may be related to the inability of the degradation products to release from the polymer surface due to the adsorbed layer of Fg in the immediate area.

\subsubsection{Potential Enzymes Involved in the Degradation of Biodegradable Polymers, Their Activities, and Half-Lives in Human Plasma}

The enzymes present in serum can be divided into two categories ${ }^{35}$ : (1) plasma-specific enzymes and (2) non-plasma-specific enzymes. The former are enzymes whose normal function is related to blood coagulation, complement activation, and lipoprotein metabolism. The latter are enzymes that have no physiological function in the plasma, whose cofactors or even substrates are not normally present in the plasma. This category includes enzymes that are secreted by tissues e.g., amylase, lipase, phosphatases — and also enzymes associated with cellular metabolism. ${ }^{35}$ Their presence in the serum at low levels may be due to the turnover of cells within the tissue causing release of the enzyme. The determination of enzyme activities in plasma has been used for clinical diagnosis since high levels of certain enzyme activities in serum may indicate tissue damage or malfunction. It should be noted, however, that increases in enzyme activities might also be due to other factors such as increased cell turnover, cellular proliferation, or decreased clearance by the kidney. ${ }^{35}$

Many of the enzymes released into the serum are normally removed at a fairly rapid rate having low half-lives. ${ }^{35}$ Table 12.1 gives some reference values for the activities of some enzymes as well their half-lives in serum.

The initial stages of certain diseases and the presence of internal injuries give rise to elevated levels of enzyme concentrations in body fluids (lymph, blood, and urine) ${ }^{35}$ Inflammation usually occurs at the biomaterial-tissue interface and reflects surface adsorption of plasma proteins, complement activation, neutrophil and macrophage infiltration, hyperplasia, and release of inflammatory mediators, free radicals, and proteolytic enzymes. ${ }^{33}$ The major enzymes associated with inflammatory cells are indicated in Table 12.2. The concentration and composition of enzymes around the implant depends on the progress of the inflammatory reaction, since each cell synthesizes specific lysosomal enzymes.

An intrinsic characteristic of natural and natural-origin polymers is their ability to be degraded by naturally occurring enzymes, which may indicate the greater propensity of these materials to be metabolized by the physiological mechanisms. ${ }^{17}$

TABLE 12.1

\section{Reference Concentration and Half-Lives of Some Enzymes in} Human Serum

\begin{tabular}{llccc}
\multicolumn{1}{c}{ Enzyme } & Concentration & Ref. & Half-Life (h) & Ref. \\
& & & & \\
Lysozyme & $4-13 \mathrm{mg} / 1$ & 27 & $16^{\mathrm{a}}$ & 39 \\
$\alpha$-Amylase & $46-244 \mathrm{U} / 1$ & 36 & $9.3-17.7$ & 40 \\
Lipase & $30-190 \mathrm{U} / 1$ & 37 & $6.9-13.7$ & 40 \\
Alkaline phosphatase (bone) & $11 \mathrm{mg} / 1$ & 38 & $30-50$ & 35 \\
${ }^{a}$ After injection into HeLa cells. & & & \\
\hline
\end{tabular}




\section{TABLE 12.2 \\ Potential Cellular Enzymes Involved in Inflammatory Response}

Enzyme
1. Proteolytic enzymes
1.1 Cathepsins (B, G, H)
(EC 3.4.22.1)
1.2 Elastase
(EC 3.4.21.11)
1.3 Neutrophil
Collagenase
(EC 3.4.24.34)
1.4 Trypsin
(EC3.4.21.4)

2. Hydrolysis of glycosides

2.1 Lysozyme (EC 3.2.1.17)
$2.2 \beta-N$-acetyl- $D$ - hexosaminidase (EC 3.2.1.52)
$2.3 \beta$ - $D$-glucuronidase (EC 3.2.1.31)

3. Hydrolysis of lipids 3.1 Lipase

(EC 3.1.1.3)

3.2 Phospholipase A2

(EC 3.1.1.4)

3.3 Cholesterol esterase (EC 3.1.1.13)

4. Others
4.1 Acid phosphatase
(EC 3.1.3.2)

4.2 Alkaline phosphatase (EC 3.1.3.1)

\section{Activity/Function in Wound Healing}

Hydrolysis of proteins, acting as an aminopeptidase (cleaving peptides bonds at specific amino acid residues).

1.1 Cathepsin B catalyses the hydrolysis of proteins with broad specificity for peptide bonds. Thiol protease is believed to participate in intracellular degradation and turnover of proteins. 1.2 Hydrolysis of proteins, including elastin, cleaving preferentially at Val-|-Xaa > Ala-|-Xaa. Medullasin modifies the functions of natural killer cells, monocytes, and granulocytes. 1.3 Cleavage of interstitial collagens in the triple helical domain. Can degrade fibrillar type I, II, and III collagens.

1.4 Cleavage of peptide bonds preferentially at Arg-|-Xaa, Lys-|-Xaa. Reduces inflammation by dissolving blood clots and extracellular protein precipitates.

2.1 Hydrolysis of 1,4- $\beta$-linkages between $N$-acetyl- $D$-glucosamine and $N$-acetylmuramic acid in peptidoglycan of the prokaryote cell walls. Lysozymes have primarily a bacteriolytic function; those in tissues and body fluids are associated with the monocyte-macrophage system and enhance the activity of immunoagents.

2.2 Hydrolysis of nonreducing end $N$-acetyl- $D$-hexosamine residues in $N$-acetyl- $\beta-D$ hexosaminides. It is responsible for the degradation of GM2 gangliosides and a variety of other molecules containing terminal $\mathrm{N}$-acetyl hexosamines, in the brain and other tissues. 2.3 Hydrolysis of glucuronic acid esters. Found diffusely in macrophages and fibroblasts, and in granular form in eosinophilic granulocytes at the implantation site.

3.1 Hydrolysis of triglycerides to partial glycerides and fatty acids. Present in macrophage cells.

3.2 Catalyzes the release of fatty acids from phospholipids. It has been implicated in normal phospholipid remodeling, nitric oxide-induced. Together with its lysophospholipid activity, it is implicated in the initiation of the inflammatory response.

3.3 Enzyme with broad specificity, acting on esters of sterols and long-chain fatty acids. Found in monocyte-derived macrophages (MDM). It is released from the lysosomes when MDM are activated during chronic inflammatory response.

4.1 Hydrolysis of phosphate esters. The acid phosphatase in normal serum is derived from blood platelets or lysis of erythrocytes and is indicative of macrophage activity at the implant site.

4.2 Hydrolysis of organic phosphate esters. Enzyme associated with plasma membrane.

Data from Price, N.C. and Stevens, L., Fundamentals of Enzymology. The Cell and Molecular Biology of Catalytic Proteins, 3rd ed., Oxford University Press, Oxford, 1999, chap. 8, 10; Cassim, B., Mody, G., and Bhoola, K.D., Pharmacol. Therap., 94, 1, 2002; Duguay, D.G. et al., Polym. Degrad. Stabil., 47, 229, 1995; Labow, R.S., Erfle, D.J., and Santerre, J.P., Biomaterials, 16, 51, 1995; Erfle, D.J., Santerre, J.P., and Labow, R.S., Cardiovasc. Pathol., 6, 333, 1997.

For instance, the degradation of hyaluronic acid in mammals is carried out by the concerted action of three enzymes ${ }^{45,46}$ : hyaluronidase, $\beta$ - $D$-glucuronidase, and $\beta$ - $N$-acetyl- $D$-hexosaminidase.

Starch and its derivatives have been widely used in the pharmaceutical industry as controlledrelease excipients for the preparation of matrix tablets, ${ }^{25,48}$ since starch can be enzymatically 
degraded by $\alpha$-amylase and other amylolytic enzymes to form water-soluble oligosaccharides, resulting in polymer erosion with the concomitant drug release. ${ }^{25,48}$ It was also shown that $\alpha$-amylase was even able to degrade chemically modified starch. ${ }^{48} \mathrm{~A}$ more detailed description about the enzymatic degradation of starch-based biomaterials will be discussed in Section 12.5.

The main enzyme involved in the degradation of chitin derivatives in the body is lysozyme. ${ }^{27}$ Although the natural substrate of lysozyme is peptidoglycan, a negatively charged polysaccharide present in the bacteria cell walls, it has been shown to have the ability to cleave glycosidic linkages of chitin derivatives to some extent, but its activity strongly depends on the degree of chemical modification..$^{27-29}$

Labow and coworkers ${ }^{22}$ had studied extensively and characterized the enzymatic hydrolysis of polyether-polyurethanes (PEU), polyester-polyurethanes (PESU), and polycarbonate-polyurethanes (PCNU) by cholesterol esterase (CE), carboxyl esterase, elastase, proteinase $\mathrm{K}$, thrombin, cathepsin $\mathrm{B}$, and phospholipase $\mathrm{A}_{2}$ enzymes. Although enzymes like elastase have been shown to be involved in the biodegradation of PUs, CE was the enzyme showing the highest activity toward these polymers, ${ }^{22}$ and further studies were carried out with this enzyme to study the effect of several parameters on the enzymatic behavior of PUs. ${ }^{26,30-32,34,42-44,49-61}$

The enzymatic hydrolysis of poly( $L$-lactic acid) (PLLA) polymers has been studied using proteinase $\mathrm{K}^{, 62-64}$ an endopeptidase enzyme responsible for the hydrolysis of peptides amides in keratin and other proteins. It was demonstrated that this enzyme was able to accelerate the hydrolysis of PLLA. ${ }^{62}$ PLLA and poly(glycolic acid) (PGA) are polymers synthesized from materials found naturally in the body, and therefore they are expected to be degraded by enzymes. Schakenraad et al. ${ }^{65}$ observed a slightly increased level of lactate dehydrogenase (LDH, an enzyme involved in the conversion of lactic acid) and its coenzyme NADH-reductase in macrophages and fibroblasts after 7 days of PLA implantation in AO/BN rats. It was suggested that the increase in LDH activity might be related to the release of $L$-lactic acid monomers and oligomers as a result of PLA degradation. This means that degradation of biomaterials may induce other enzyme activities besides the enzyme patterns observed in the early stages of implantation, which are simply related to wound healing reaction.

Lipase is an enzyme that is able to catalyze the hydrolysis of ester bonds in polyesters when in the presence of an aqueous media ${ }^{63}$ It was found that certain lipases enhanced the degradation of polycaprolactone (PCL) when compared with incubation in buffer only. ${ }^{66,67}$ The enzymatic hydrolysis of PCL occurs mainly at the polymer surface since it is difficult for a hydrophilic enzyme to diffuse into a hydrophobic polymer like PCL. ${ }^{37}$ The surface erosion mechanism of PCL demonstrated by lipase enzyme may be useful to deliver bioactive agents by an enzymatically controlled process.

Polyphosphates are a class of biodegradable polymers with a phosphodiester backbone, which is prone to hydrolytic enzymes such as phospholipases and phosphodiesterases.$^{68}$ Renier and Khon ${ }^{68}$ studied the degradation kinetics of a biodegradable polyphosphate in fetal bovine serum (FBS) and postulated that alkaline phosphatase present in serum may cleave the phosphodiester linkage of the backbone of polyphosphate polymers.

\subsection{IN VITRO STUDIES TO ASSESS THE DEGRADATION KINETICS OF BIODEGRADABLE POLYMERS}

In vitro degradation tests of biodegradable polymers in simple aging media are normally conducted to predict the performance of such polymers in the clinical situation. Taking into account the complexity of the body fluids, it is common to find different results when the same materials are studied both in vitro and in vivo. For instance, it has been observed that in vivo degradation rates of a linear copolymer of lactide and ethylphosphate ${ }^{69}$ and of poly(lactide-co-glycolide) microspheres ${ }^{11}$ were faster in vivo than in vitro. The higher in vivo degradation rates of biomaterials 
have been explained by the effects caused by cellular and enzymatic activities found in the body and to the dynamic loads experienced by devices during the implantation period. Opposite behaviors were found by Jiang and coworkers ${ }^{70}$ who reported that the in vivo degradation of poly(esteranhydrides) based on aliphatic and aromatic diacids was slower than in vitro. The lower in vivo degradation might be related to the prevention of water penetration and diffusion of degradation products by the formed capsule around the implanted materials in vivo. Hooper et al. ${ }^{71}$ found, however, similar in vitro and in vivo degradation rates of tyrosine-derived polymers (poly[DTE carbonate] and poly[DTE adipate]), which confirmed the absence of enzymatic hydrolysis in the degradation process of these materials. The differences found between in vitro and in vivo results are possibly related to the intrinsic properties of each biomaterial and with the in vitro systems used to simulate the in vivo conditions. Nevertheless, in vitro results may constitute a useful approach to predict the degradation rate of biomaterials and also a guideline for planning in vivo studies.

Most of the degradation studies reported in the literature are performed by incubating the material in phosphate buffer saline (PBS) solution. In this way, it is expected that only degradation by normal hydrolysis will occur. Hooper and colleagues ${ }^{71}$ found that both PBS and simulated body fluid (SBF) solutions were appropriate incubation buffers for an accurate simulation of the in vivo degradation of tyrosine-derived polymers. Nonbuffered solutions (water, isotonic saline solutions) have been also used in many degradation studies, but these tests had ignored the buffer capacity of body fluids. Furthermore, many of the degradation tests do not contemplate the renewal of the degradation medium, and again, such testing protocols do not allow for the evacuation of degradation products by fluid flow, intrinsic to in vivo conditions. ${ }^{9}$

Another important issue is the mass/volume ratio used in the degradation tests. Different mass/volume ratios have been reported in the literature, and this may affect the degradation kinetics of biomaterials. It is known, for instance, that articular cartilage tissue is quite avascular, ${ }^{9,72}$ which means a low level of surrounding fluids.

The choice of the incubation media, mass/volume ratio, and duration of the in vitro degradation studies should take into account the locale where the materials will be implanted and the time that the materials will be in contact with the tissues and body fluids. For instance, the release of acidic degradation by-products in anatomical regions, without access to sufficient quantities of body fluids, might overwhelm the capacity of the body fluids to ensure local buffering and cause adverse effects to the surrounding tissues. ${ }^{9}$ Nevertheless, the use of other degradation solutions (water, serum, enzyme buffer, ionic and simulated body fluid solutions) may provide insight into some aspects of the degradation process of certain biomaterials since enzymes and other reactive species are expected to be present in the in vivo environment (please see Section 12.3.3.2).

Another focus of controversy is the use of static or agitation conditions during the degradation tests. The level of agitation may influence the degradation kinetics of biomaterials since it facilitates the release of degradation products from the bulk or surface of the material to the solution. Furthermore, in the case of enzyme-mediated degradation, agitation promotes the contact between the soluble free enzyme and the insoluble substrate (biomaterial) enhancing adsorption. It is assumed that the body fluids move slowly in soft and hard tissues, and it is suggested that degradation tests should be performed under static ${ }^{16}$ or slow agitation (two rotations per minute) ${ }^{73}$ to mimic the physiological conditions. On the other hand, the use of different agitation conditions during the ex vivo growth of tissues (static flasks, mixed flasks, rotating vessels, flow-perfusion bioreactors) has been reported. It was observed that cartilage constructs cultured in a dynamic laminar flow field in rotating vessels led to better results (in terms of size, mechanical properties, and higher content of collagen and glycosaminoglycan) than static and agitated flasks. ${ }^{74}$ In addition, it is expected that biomaterials will experience some fluid flow and repetitive loading when under in vivo conditions, ${ }^{74}$ and this is likely to influence the degradation kinetics of biodegradable polymers. The study of the degradation behavior of biomaterials under these different incubation conditions is, therefore, important to investigate the adequacy and efficacy of the material during 
cell culture and implantation. Furthermore, these studies may also provide additional information about the degradation mechanisms of the materials.

Agrawal et al. ${ }^{74}$ studied the effect of fluid flow on the in vitro degradation kinetics of $\operatorname{poly}(D, L$ lactide-co-glycolide) (PLG) scaffolds. Contrary to what might be expected, it was observed that the fluid flow decreased the degradation rate significantly. This result was attributed to the absence of the autocatalytic effect ${ }^{6,10,16,63}$ caused by the acidic by-products formed during hydrolysis of PLG copolymers under flow conditions, since in this situation it is likely that the degradation products are washed away. Different results may be obtained when studying other polymeric systems, since it is expected that the effect of fluid flow may cause additional mechanical stress and contribute to the leaching out of processing additives and fast release of degradation products, leading to increased degradation. The degradation rate of a particular biomaterial under these conditions may not, however, follow any of these behaviors, and only an accurate test may give indications on the type of degradation.

The number of samples tested should always allow for a valid statistical analysis $(n>10)$, and a proper control for each test period should always be used.

The great diversity of the conditions used in the various degradation studies does not allow for direct comparisons to be made, and the use of standardized methods for characterizing the degradation properties of biomaterials would be advisable. The ISO standards 10993-975 and 10993-1376 provide guidance on general requirements for the design of tests to assess the degradation of biomaterials and to identify and quantify the degradation products from polymers, respectively. It is also mentioned in these standards that, due to the wide range of polymeric materials used in biomedical applications, the degradation tests should be carried out under conditions that closely simulate the environment in which the material is going to be used and that conditions should reflect the intended function of the material.

\subsubsection{Degradation-Monitoring Techniques}

After implantation, biodegradable polymers may undergo a variety of changes in their physicochemical properties as a result of degradation. These alterations may compromise their desired function and evoke undesirable tissue response. It is important, therefore, to characterize and quantify the changes that occur in the biomaterial at different stages of degradation and to evaluate the corresponding tissue response, since the tissue reaction may change during the course of the degradation process. Hooper et al. ${ }^{71}$ observed that the tissue response of poly $(L$-lactic acid $)$ and poly(DTE adipate) after 60 days was not significantly different but, for the same degree of degradation, evident differences on the tissue response were found.

In the early stages of degradation, the event with most significance is the gradual diffusion of water solution into the polymer matrix (leading to an increase of water uptake), while little changes occur in the sample mass, in the molecular weight, and consequently in the polymer tensile strength. The main changes are related to the ones occurring at the polymer surface, such as an increase of the surface roughening and surface free energy and eventually some chemical changes due to hydrolysis. The second stage of the degradation process is characterized by a decrease in the polymer molecular weight, as a result of chain scission and by the diffusion of larger-molecular-weight fragments to the solution. This leads to increased weight loss and porosity of the matrix and loss of tensile strength. Advanced stages of degradation are characterized by collapse of the polymer matrix and dramatic decrease in molecular weight and an increase in weight loss. Crystallinity substantially disappears, and as a consequence, there is a marked decline in the mechanical properties. ${ }^{77}$

The main techniques used to evaluate the degradation of biomaterials can be divided into surface analysis (infrared spectroscopy, X-ray photoelectron spectroscopy, contact angle measurements), which are more appropriate to monitor the changes occurring in the first stages of degradation, and bulk analysis (determination of changes in molecular weight, weight loss, temperature transitions, 
mechanical properties) for characterizing the later stages of degradation. Therefore, the selection of the characterization techniques should be made based on the degradation stage and also on the unique properties of the biomaterials under investigation. Some of the most common properties and techniques used to evaluate the course of degradation of biodegradable polymers are described in the following section.

\subsubsection{Water Absorption and Weight Loss}

The main factors influencing the wettability of polymers are related to their degree of crystallinity, chemical composition, and aqueous media. Marois et al. ${ }^{78}$ found different water absorption behaviors for polyhydroxyoctanoate (PHO) films in water and in PBS solution. It was observed that incubation in PBS led to lower water absorption than when incubated in water, and this difference was attributed to osmotic phenomena and to the ionic strength of the PBS. The same behavior was obtained by $\mathrm{Li}^{16}$ with PLA $_{50}$ (L-LA/D-LA, 50/50) polymers.

Water uptake measurements can give, therefore, some indication of the hydrophilicity/hydrophobicity nature of the materials and therefore of their tendency to be degraded by hydrolysis. The water uptake values are normally obtained after equilibrium of the materials in solution. In some cases, the equilibrium cannot be reached because the material is degrading at the same time. In this case, the level of water uptake usually increases with the degradation time due to an increase in the permeability of the materials (a porous structure is normally obtained as a result of the release of degradation products).

During degradation, the mass of the material may undergo changes, and these changes can be monitored by comparing the mass before and after the degradation period. The material should be dried to a constant mass before measuring the initial weight of the sample to avoid residual moisture in the samples. The drying temperature should not exceed the temperature at which the materials undergo irreversible changes (e.g., melting temperature). After degradation, the sample should be washed thoroughly with distilled or deionized water to remove traces of soluble degradation products, enzymes, salts, or other impurities and dried under vacuum conditions until constant weight. The extent of degradation is commonly determined by calculating the percentage of weight loss.

\subsubsection{Molecular Weight}

The determination of the polymer molecular weight $\left(\mathrm{M}_{\mathrm{w}}\right)$ during the degradation process is one of the most important analyses to be made when studying the degradation mechanisms of polymeric biomaterials. Many other properties are affected by changes to the $M_{w}$, including mechanical properties, crystallinity, weight loss, and morphology. The evolution of $\mathbf{M}_{w}$ during degradation can be determined by gel permeation chromatography (GPC) or by viscometry techniques. The main useful parameters to be analyzed are the number-average $\left(\mathrm{M}_{\mathrm{n}}\right)$ and the weight-average $\left(\mathrm{M}_{\mathrm{w}}\right)$ molecular weights. The ratio $\mathrm{M}_{\mathrm{w}}$ to $\mathrm{M}_{\mathrm{n}}$ is known as the polydispersity index, which measures the breadth of the molecular weight distribution.

\subsubsection{Crystallinity}

In semicrystalline polymers, an increase in polymer crystallinity has been frequently observed at early stages of degradation, $, 16,79$ and this is likely related to the plasticizing effect of the absorbed water that makes chain movements possible, allowing crystallization to proceed toward thermodynamic equilibrium. ${ }^{78}$ On the other hand, initial hydrolysis takes place at the amorphous regions, since these regions are more accessible to water molecules and enzymes, leading to an initial increase in the crystallinity of the polymer. ${ }^{15,16}$ The generation of crystallized monomers and oligomers was also indicated as a source for increased crystallinity after degradation. ${ }^{8}$ As chain 
scission occurs in the crystalline regions, during later stages of degradation, a decrease in the overall crystallinity of the polymer can be expected. ${ }^{77}$

The changes in the crystallinity of biodegradable polymers after degradation can be followed, among other techniques, by differential scanning calorimetry (DSC) or by wide-angle x-ray diffraction (WAXD).

The analysis of crystallinity conducted by DSC is made based on changes in the glass transition temperature $\left(T_{g}\right)$, crystallization temperature $\left(T_{c}\right)$, and melting temperature $\left(T_{m}\right)$ and on the heat of fusion $(\Delta \mathrm{H})$ values.

The shift, disappearance, or appearance of new and broader peaks in WAXD patterns is an indicator of a change in the crystallinity.

The percentage of crystallinity may be derived from DSC and WAXD data using empirical correlations.

\subsubsection{Morphology and Dimensional Changes}

Changes in the surface morphology of biomaterials after degradation, like roughness and the appearance of cracks or micro/macropores, may be examined by microscopy methods such as light microscopy, scanning electron microscopy (SEM), and atomic force microscopy (AFM). In addition, AFM gives information about the sample topography at low magnifications and allows for roughness calculations. ${ }^{59}$

The measurement of sample dimensions during the degradation process may be an important parameter to be analyzed since, in some cases, degradation can cause dramatic morphologic changes that may compromise the macroscopic properties of the final implant (e.g., bone cements or other filler/fixation devices). This analysis can also provide information about the mode and direction of the degradation font ${ }^{80}$ Changes within the material may be analyzed by observing the sample cross section obtained by freeze-fracturing in liquid nitrogen.

\subsubsection{Surface Chemistry}

The surface chemistry of biodegradable polymers, before and after degradation, can be analyzed by several techniques that include Fourier transform infrared (FTIR) spectroscopy, X-ray photoelectron spectroscopy (XPS), and contact angle measurements. The main difference between these techniques is related to the amount of information provided and the depth of sample analyzed. XPS analysis can give information about the elemental and chemical group composition at the material surface (first $10 \mathrm{~nm}$ of surface), and the depth of penetration can be varied by the takeoff angle, allowing the construction of depth profiles over the outermost polymeric surface. ${ }^{51,58}$ FTIR with attenuated total reflectance (ATR) can provide information for chemical groups within the top 5 $\mu \mathrm{m}$ of the surface. ${ }^{3,30}$ In addition, reflection mode (FTIR-ATR) allows for the analysis of samples in the wet state, which is more relevant from the biological point of view..$^{30,31}$ The ability to characterize the chemical state of wet surfaces is rather useful to analyze the mechanism by which water could penetrate and disturb the structure of the materials. It is also known that polymer surfaces gradually change toward a more hydrophilic structure in polar aqueous environments. ${ }^{81}$ For example, it was observed by Tang and colleagues ${ }^{31}$ that, after exposure to water, some polycarbonate-polyurethanes showed an increase in hydrogen-bonded carbonate carbonyls.

Contact angle measurements may give an indication on changes in the hydrophilicity of the material surface. Higher contact angle values (which can be obtained in static sessile drop or dynamic conditions using both the advancing and the receding contact angle) indicate generation of a more hydrophobic surface.

The choice of technique depends, therefore, on the amount of information provided by each technique, its availability, and its associated cost. 
Surface chemistry characterizing techniques may give indications about the type of degradation mechanism. ${ }^{7,70,78,82}$ Marois et al. ${ }^{78}$ have used FTIR to analyze chemical changes in the structure of polyhydroxyoctanoate (PHO) films after degradation in aqueous media, and this technique indicated that the possible degradation mechanism of this material began internally, moving outwardly to the surface.

\subsubsection{Mechanical Properties}

Certain biomedical applications, such as hard tissue replacement, require biodegradable materials with mechanical properties typically on the same order of magnitude as those of the tissue that it replaces. In addition, the material should degrade while maintaining a specified minimum mechanical strength to support the formation of new tissue. Thus, in these cases, it is critical to evaluate the mechanical performance of biomaterials during the course of their degradation. Currently, the techniques described in the American Society for Testing and Materials (ASTM) standards have been the most commonly used for testing tensile, bending, and compressive properties of polymeric biomaterials. ${ }^{83}$

\subsubsection{Isolation and Identification of Degradation Products}

The development of materials for biomedical applications always requires extensive biological testing to demonstrate the safety of both the material and its degradation components. ${ }^{84} \mathrm{~A}$ potential disadvantage of using biodegradable polymers in biomedical applications is the eventual toxicity of the degradation products. If the biomaterial degrades, either spontaneously or due to biological activity, components can leach into surrounding tissues and may enter the circulation and be easily metabolized via normal pathways, causing toxic effects systemically and in distant sites. ${ }^{33}$ It is necessary, therefore, to identify the major species produced at different stages of degradation and the kinetics of their formation. In addition, the release and accumulation of degradation products may interfere with the course of degradation and with the equilibrium of degradation reactions. The release and accumulation of some degradation products may accelerate the degradation rate of some biomaterials. For example, the release of carboxyl end groups formed by chain cleavage of lactide and glycolide aliphatic polyesters during hydrolysis may produce a decrease in the local $\mathrm{pH}$ and further catalyze the hydrolysis of other ester bonds, a phenomenon called autocatalysis. ${ }^{6,10,16,63,80,83}$ On the contrary, Yaszemski et al. ${ }^{85}$ observed that the mechanical properties of a poly(propylene fumarate) (PPF)-based composite material increased with degradation time, which was explained by a crosslinking effect promoted by complexation between carboxylic groups, formed from PPF degradation and accumulated in the incubation solution, with divalent calcium ions released from $\beta$-tricalcium phosphate $(\beta-\mathrm{TCP})$. Another possibility is the potential inhibitory effect of degradation products on enzyme-catalyzed reactions. For example, it is known that the hydrolysis by-products of starch (maltose and maltotriose) strongly inhibit the activity of $\alpha$ amylase. ${ }^{25}$ The release of processing additives or other degradation products may also have a denaturation effect on enzyme activity. Taking into account the occurrence of such effects, the renewal of degradation liquors may have, therefore, a significant impact on the degradation kinetics of certain biomaterials.

The content of degradation solutions depends mainly on the material tested, the degradation stage, and the incubation solution used in the degradation studies. It might contain degradation products, enzyme, proteins, enzyme impurities, salts, and debris. The degradation solutions can be subjected to appropriate chemical and physical analysis such as high-performance liquid chromatography (HPLC), UV-visible spectrophotometry, nuclear magnetic resonance (NMR), mass spectroscopy (MS), or other analytical methods to identify and, if possible, quantify the main degradation products. It may be necessary, before these analyses, to perform separation techniques for the removal of salts, processing additives, monomers, oligomers, residual solvent released into the 
degradation solutions, or proteins and enzymes, since the presence of these components may interfere with the identification and quantification of degradation products. Ultrafiltration membranes can be used to separate high-molecular-weight components, such as proteins, from watersoluble low-molecular-weight degradation products in the incubation media.

Analysis and quantification of the degradation products released into the incubation medium also provide information about the modes of action of enzymes on the polymer and what linkages are more susceptible to hydrolysis. The enzymatic degradation of polyurethanes has been assessed by means of following the radioactive release of ${ }^{14} \mathrm{C}$-labeled degradation products. ${ }^{26,30-32,34,42-44,49-61}$ The determination of soluble reducing sugars may be used to assess the enzymatic hydrolysis of polysaccharides. ${ }^{48,86}$

HPLC and MS techniques have been successfully used on the isolation and identification of the degradation products of biodegradation of polyurethanes by cholesterol esterase. ${ }^{50,56,57}$

Chaubal and coworkers ${ }^{69}$ followed the generation of water-soluble degradation products during the in vitro degradation of a linear copolymer of lactide and ethylphosphate by NMR.

\subsubsection{Mechanisms of Degradation}

In general, the first degradation event after contact with water molecules is the hydrolytic scission of the polymer chains leading to a decrease in the molecular weight. At this initial stage, the first degradation products are not small enough to become soluble, and no significant change in the material weight is detected. With increasing time, the molecular weight of degradation products is reduced by further hydrolysis, which allows them to diffuse from the bulk material to the surface and then to the solution, causing significant weight loss.

Polymers can be degraded by bulk degradation ${ }^{6,8,9,62}$ or surface erosion mechanisms. ${ }^{6,79,80,82,87}$ Bulk degradation is characterized by hydrolysis of chemical bonds in the polymer chain at the center of the material, which typically results in an empty shell but maintains their size for a considerable portion of time. ${ }^{16}$ This degradation behavior has been observed for polylactides polymeric systems, whose degradation mechanisms are well described in the literature. ${ }^{6,8,15,16}$

Degradation by surface erosion mechanism is characterized by loss of the material from the surface only, resulting in very predictable mass loss profiles. The materials get smaller but keep their original geometric shape. This feature may be beneficial for delivering molecules at constant rate and maintaining the mechanical and structural integrity of the material with degradation. Poly(anhydrides) and poly(orthoester)s are examples of surface-eroding polymers. ${ }^{6,79,80,87}$

Enzyme-catalyzed degradation of polymeric biomaterials may follow a surface erosion mechanism, especially for highly crystalline and hydrophobic homopolymers. Due to their relatively large size, the enzyme molecules cannot penetrate the tightly packed structure of certain polymers, so that the enzymatic catalysis occurs at the polymer-enzyme interface. As the degrading surface becomes roughened or fragmented, enzymatic action may be enhanced as a result of increased surface area. Enzymatic degradation mechanisms of polymeric materials depend, however, on many other factors such as chemical composition, degree of homogeneity, and processing technique.

Several different types of models have been applied to describe the degradation kinetics of biodegradable polymers, 2,6,10,42,68,88 assuming first- or second-order kinetics. Recently, computer modeling has also been used, but some of these models did not consider diffusion theory to describe transport phenomena. ${ }^{6}$ The mathematical model proposed by Duguay and coworkers ${ }^{42}$ describes, in a very complete and comprehensive way, the in vitro enzymatic degradation of biomedical polyurethanes by a single enzyme.

Despite the progress made on mathematical models to predict the degradation of biodegradable polymers, much more data and sophisticated models are needed to apply these approaches to other polymeric systems. 


\subsubsection{Strategies for Controlling the Degradation Rate of Biodegradable Polymers}

Depending on the application (long-term implants or temporary matrices for tissue engineering and drug delivery), three main strategies have been observed to alter the degradation rate of biodegradable polymers. Some strategies intend to increase the degradation rate of biomaterials, and this is normally obtained by blending or copolymerization techniques or by adjusting the polymer physicochemical properties. The reduction of the degradation is mainly achieved by selecting the polymer chemical composition (high degree of crystallinity, hydrophobicity, elevated molecular weight, nonhydrolysable bonds) and by using surface modification methods. The third approach may be obtained by selecting the right combination of the other two strategies and may take advantage of using smart systems, which means that polymers will degrade only in response to a certain stimulus.

The degradation of some biomaterials involves nonenzymatic hydrolysis, which is largely nonregulated. ${ }^{89}$ In such situations, only the calendar may determine the rate of resorption of the material, and in these cases, the degradation of biomaterials is controlled by manipulating their physicochemical properties. Blending and copolymerization have been used to change the degradation rate of polymeric materials, since, in general, blends and copolymers degrade faster than homopolymers from the same family.

Other approaches ${ }^{90,91}$ have been used, such as including enzymatic recognition sites in polymer backbones (e.g., amino acids) to enzymatically modulate the material degradation or making the material sensitive to the feedback provided by the cells involved in the healing response, ${ }^{92}$ as cells enzymatically degrade the extracellular matrix around them.

It has been observed that the inclusion of some substances into polymeric matrices, either as excipients or drugs for controlled delivery, may change the degradation rate of some biomaterials. The inclusion of sodium, ${ }^{9}$ calcium, ${ }^{9}$ or zinc carbonate $^{11}$ into poly(lactide-co-glycolide) (PLG) polymers was shown to retard the degradation of PLG due to the neutralization of carboxylic acid groups formed during PLG hydrolysis by the basic salts, consequently avoiding the autocatalytic effect of the acidic degradation products. Birnbaum and Brannon-Peppas ${ }^{12}$ found that the inclusion of increasing amounts of epirubicin $\mathrm{HCl}$ in poly(lactic-co-glycolic acid) (PLGA) nanospheres hastened their degradation. This may be caused by an increase in water uptake due to the free space for water to diffuse into the interior of the nanoparticles after drug dissolution and release.

For instance, the combination of a series of surface-modifying macromolecules, containing fluorinated end-groups, into a base polyurethane reduced the material's susceptibility to enzymatic hydrolysis. ${ }^{51,52}$

Kamimura et al. ${ }^{93}$ developed a self-regulated degradation system based on dextran (Dex) with a model oxidant dihydronicotinamide (NAH) to achieve nonlinear enzymatic degradation and consequently an oscillative drug release system. The smart system had used the combined activities of three enzymes (dextranase, isomaltase, and glucose oxidase) to generate oxidant degradation products $\left(\mathrm{H}_{2} \mathrm{O}_{2}\right)$ able to oxidize NAH-Dex (NA+-Dex), which was then complexed with carboxymethyl dextran (anionic polysaccharide) to form polyion complexation, consequently eliminating further enzymatic degradation of NAH-Dex.

Materials to be used in some applications, such as hard-tissue replacement, must combine adequate mechanical properties with controlled biodegradability. It may be difficult to achieve the desired combination of degradation and physical properties for a single material. In this context, it may be useful to incorporate specific enzymes into the materials by different immobilization methods to control their degradation rate (this approach will be presented and discussed in the next section). 


\subsection{ENZYMATIC DEGRADATION OF STARCH-BASED BIOMATERIALS - A CASE IN STUDY}

Starch-based polymers have been studied and proposed as potential materials to be used in several biomedical applications. ${ }^{94-103}$ They have shown great versatility, are easily processed, and have been proposed for applications such as drug delivery carrier systems, ${ }^{95-97}$ hydrogels and partially degradable bone cements, ${ }^{97,98}$ materials for bone replacement/fixation or fillers for bone defects, ${ }^{98}$ and porous structures to be used as scaffolds in tissue engineering of bone and cartilage. ${ }^{99}$ The degradation behavior of starch-based biomaterials in different shapes and compositions (porous structures, ${ }^{96,99}$ hydrogels, ${ }^{95,97}$ bone cements, ${ }^{98}$ chemically modified samples, ${ }^{100,101}$ compact samples, ${ }^{102}$ composites ${ }^{103}$ ) has been assessed in different degradation media (namely isotonic saline solution, ${ }^{96-101,103}$ with or without bovine serum ${ }^{102}$ ). The degradation rate of these materials was shown to be dependent on certain parameters such as porosity, hydrophilicity, chemical composition, and degree of chemical modification. ${ }^{96-101}$ The susceptibility of these starch polymeric blends to enzymatic degradation was reported recently. ${ }^{86}$

In this section, some experimental work, regarding the susceptibility of starch-based polymers to enzymatic degradation, will be presented and discussed. The main aim of these studies was not to simulate the degradation of the material in vivo, but to investigate whether starch polymeric blends could be degraded by certain enzymes with the aim of developing strategies to control their degradation rate by enzymatic means. Furthermore, these studies may also provide insight into the mechanistic aspects of the enzymatic degradation of these materials.

\subsubsection{Materials and Methods}

The material used in this work was a polymeric blend of corn starch with poly(e-caprolactone) (SPCL, 30/70 wt \%). The blend was processed by conventional injection molding to produce compact discs $(\varnothing=1 \mathrm{~cm})$. The samples were incubated in phosphate buffer saline (PBS) solution (0.01 M, pH 7.4) containing enzyme at concentration of $0.6 \mathrm{mg} / \mathrm{ml}$ (lipase from Thermomyces lanuginosus, Novozymes A/S, Bagsvaerd, Denmark; $\alpha$-amylase from Bacillus amyloliquefaciens, Genencor International, Rochester, NY, U.S.) at $37^{\circ} \mathrm{C}$ with constant shaking at $60 \mathrm{rpm}$ for 6 weeks. A control was also performed by incubating the samples in buffer alone. After degradation, the samples were washed with distilled water and allowed to dry inside a desiccator until constant weight was reached. The surface morphology of the samples after enzymatic degradation was examined using scanning electron microscopy (SEM). The changes in the chemical composition on the surface of starch-based polymers, before and after enzymatic degradation, were analyzed by Fourier transform infrared (FTIR) spectroscopy with attenuated total reflectance (ATR) device.

With the aim of tailoring the degradation rate of starch-based biomaterials, another set of experiments was performed by encapsulating a thermostable $\alpha$-amylase in the SPCL matrices using a melt-processing method. The encapsulant enzyme was a thermostable $\alpha$-amylase (Genencor International, Rochester, NY, U.S.) derived from a genetically modified strain of Bacillus licheniformis. The lyophilized enzyme was mixed with the polymer in powder form at different weight percentages $(0.5$ and $5 \%)$ and processed by compression molding $\left(P=4 \mathrm{~kg} / \mathrm{cm}^{2}, T=90^{\circ} \mathrm{C}, 20\right.$ $\mathrm{min}$ ) to prepare capsules (discs of $\approx 0.25 \mathrm{~g}$ ). A control, without encapsulated enzyme, was also performed. The samples were then immersed in acetate buffer solution $(0.1 \mathrm{M}, \mathrm{pH} 5.5)$ and incubated at $37^{\circ} \mathrm{C}$ for different periods of time. Matrix degradation was assessed by determination of weight loss, and the morphology of the sample surface was examined by SEM.

\subsubsection{Results And Discussion}

Starch is a glucose homopolymer composed of amylose and amylopectin. The former is an essentially linear structure where the glucose units are joined by $\alpha(1 \rightarrow 4)$ glycosidic links, while amylopectin consists of linear $\alpha(1 \rightarrow 4)$ linked glucose chains, but is a branched molecule with $\alpha(1 \rightarrow 6)$ 

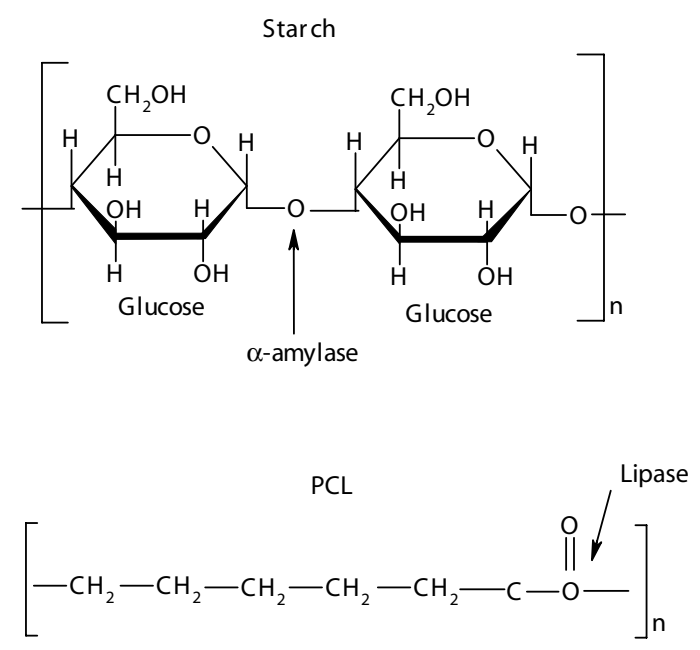

FIGURE 12.1 Schematic representation of the starch degradation by $\alpha$-amylase and PCL by lipase.

branch points every 24 to 30 glucose residues on average. The main enzymes involved in starch hydrolysis are $\alpha$-amylases, $\beta$-amylases, glucoamylases, $\alpha$-glucosidases, and other debranching enzymes (pullulanase and isoamylase). ${ }^{104} \alpha$-Amylase is an endo-specific enzyme that catalyzes the hydrolysis of $\alpha$-1,4-glycosidic linkages of starch to maltose and dextrins, reducing the molecular size of starch (Figure 12.1). ${ }^{48}$ In humans, the enzyme occurs in a variety of tissues, but the highest concentrations are in the pancreas and in salivary glands. ${ }^{35}$ Low amylase activities are normally detected in the serum (Table 12.1) of healthy subjects, but the concentration of $\alpha$-amylase in serum increases in individuals with acute pancreatitis or suffering from other disorders (alcoholism, gastrointestinal disease, etc.). ${ }^{105}$

PCL is a biodegradable aliphatic polyester with important applications in the biomedical area whose chemical structure is represented in Figure 12.1. The natural function of lipases is the hydrolysis of triglycerides to partial glycerides and fatty acids. Serum lipase is mainly derived from the pancreatic acinar cells, but other sources of lipase in the human body are the digestive tract, adipose tissue, lung, milk, and leukocytes. ${ }^{40}$

Figure 12.2 shows the IR spectra of SPCL before and after degradation in different incubation solutions. The SPCL spectrum exhibits the characteristic peaks of PCL and starch. The relevant bands of starch are the ones related to $\mathrm{OH}$ group $\left(3450 \mathrm{~cm}^{-1}\right)$ and the band at $1150-1040 \mathrm{~cm}^{-1}$ corresponding to $-\mathrm{C}-\mathrm{O}-\mathrm{C}-$ of glycosidic bonds. ${ }^{106}$ The characteristic peaks of PCL are located at $1740 \mathrm{~cm}^{-1}$, corresponding to the $\mathrm{C}=\mathrm{O}$ stretch ester carbonyl group. The peaks at $1600-1580 \mathrm{~cm}^{-1}$ and $1200-1000 \mathrm{~cm}^{-1}$ are related to asymmetric stretch of $-\mathrm{COO}-$ and the stretch of $-\mathrm{C}-\mathrm{O}$ bond at the main polymer chain. ${ }^{107}$

It is possible to observe that, after incubation in PBS solution, no significant changes occurred in the chemical composition of the surface of SPCL material. The effect of $\alpha$-amylase can be observed by a decrease in the intensity of the peak at $1150-1040 \mathrm{~cm}^{-1}$, indicating the action of $\alpha$ amylase in cleaving the glycosidic linkages of starch. It is possible to visualize also a decrease of intensity on the peak of $\mathrm{OH}$ group. After incubation with lipase, the main effect observed is a significant decrease on the ester band and also on the characteristic bands of the bonds occurring at the polymer chain (1600-1580 and 1200-1000 $\mathrm{cm}^{-1}$ ). The combination of the two enzymes contributes to significant differences both on the bands of starch and PCL, indicating degradation of both components of the polymeric blend.

The incubation of SPCL in different solutions also causes distinct surface morphologies, which can be seen in the SEM micrographs (Figure 12.3). The incubation in buffer only (control sample) does not cause visible changes in the sample morphology. The sample incubated with $\alpha$-amylase 


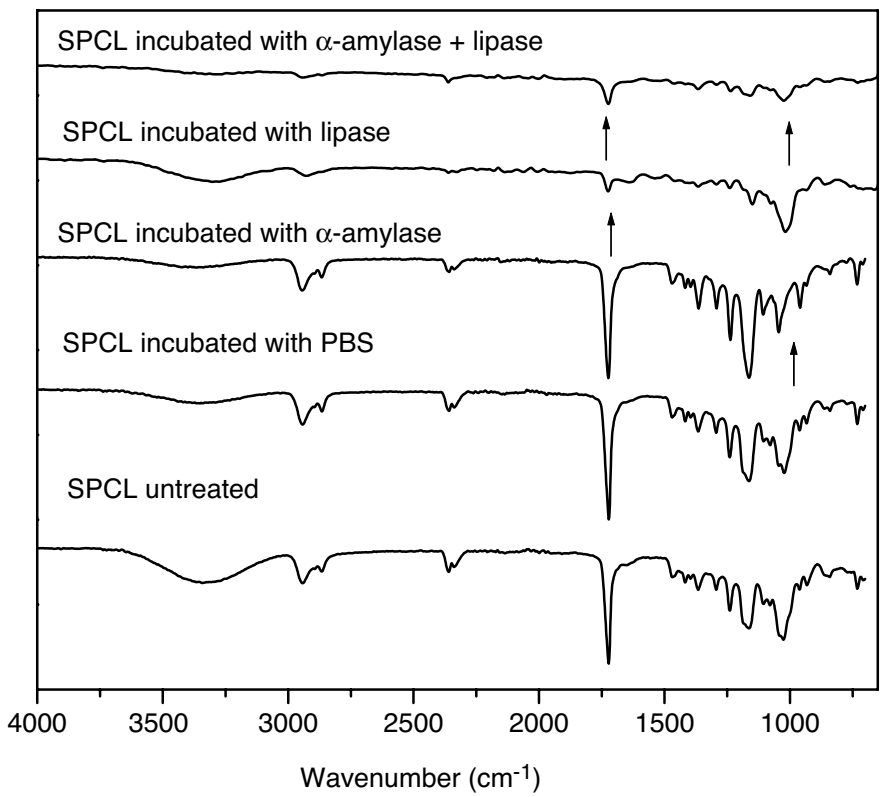

FIGURE 12.2 IR spectra of SPCL material before and after enzymatic degradation with $\alpha$-amylase and lipase.
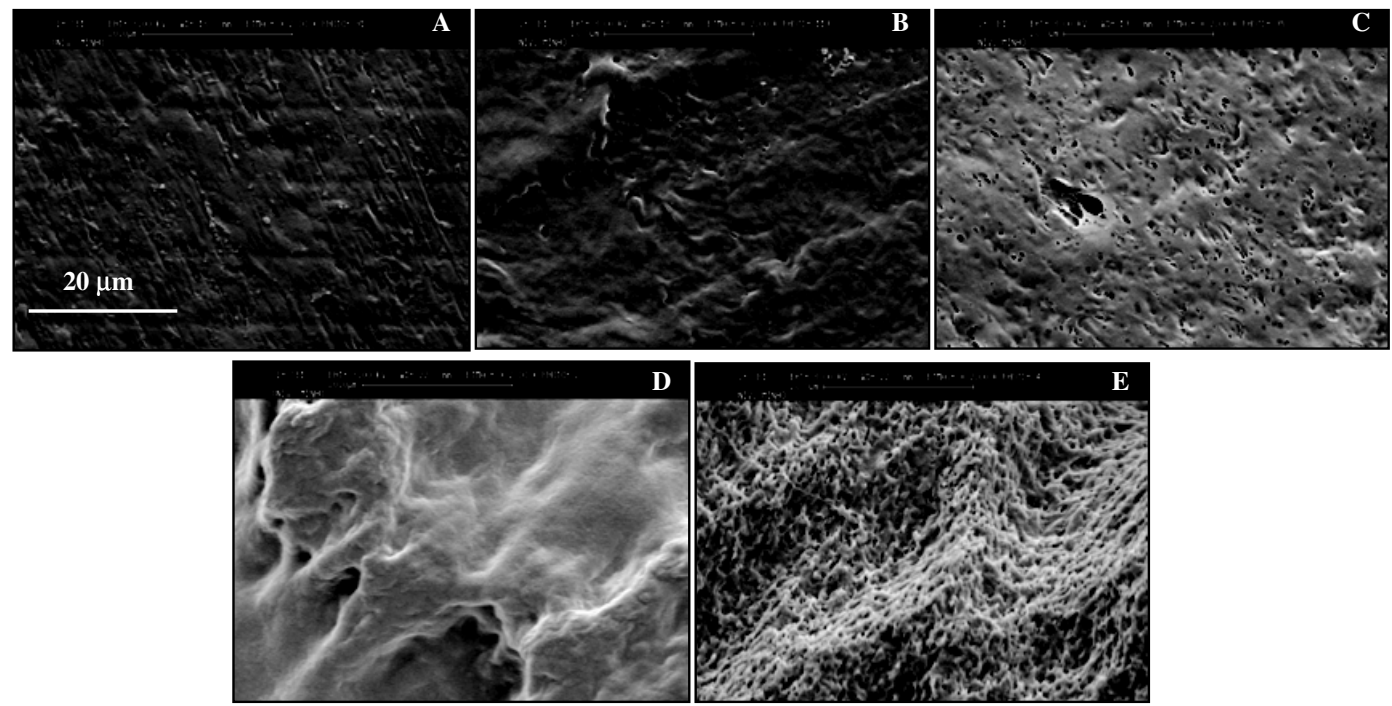

FIGURE 12.3 SEM micrographs of SPCL surface before and after degradation in different incubation solutions for 6 weeks. Magnification $\times 2000$. A) Untreated sample; B) PBS; C) $\alpha$-amylase; D) lipase; E) $\alpha$-amylase and lipase.

shows some small pores at the surface, which are probably related to the degradation of starch. Although not visible at higher magnification, samples incubated with lipase exhibited the presence of large fissures on the surface. At high magnification $(2000 \times)$, it is possible to detect changes in the surface topography. Combining both enzymes, it is possible to observe a surface with different topography and with small pores indicating the distinct effects of each enzyme.

Enzyme encapsulation/immobilization can be used to tailor the material degradation and, at the same time, provide controlled-release systems of active organic and inorganic substances at a 


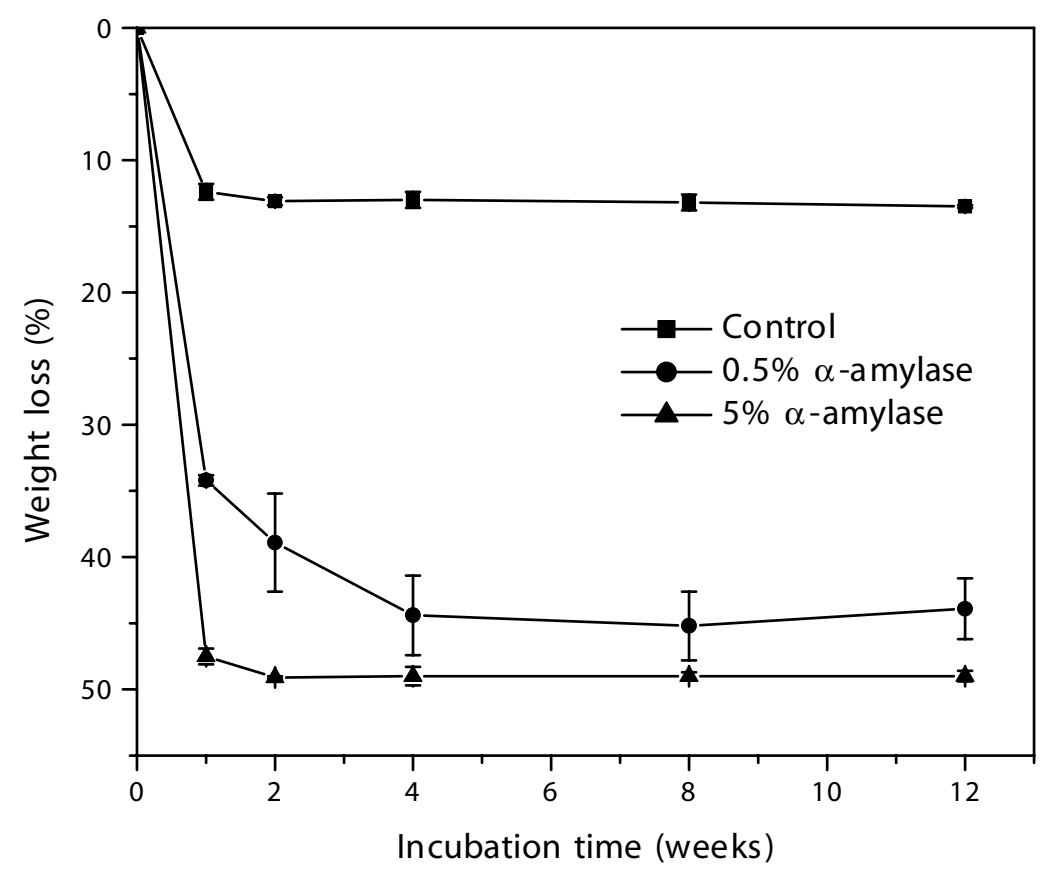

FIGURE 12.4 Degradation profile ( $\left.\mathrm{pH} 5.5,37^{\circ} \mathrm{C}\right)$ of SPCL discs, measured as weight loss, containing different percentages of encapsulated $\alpha$-amylase.

desired site and time and at a specific rate. Figure 12.4 presents the degradation behavior of SPCL capsules in the different conditions studied. The control sample exhibits a significant weight loss (about 13\%) during the first week, but the sample mass tends to remain almost constant in the following weeks. The original fast weight loss is related to the leaching of plasticizers and to the release of some oligomers due to some thermal degradation of the material that occurs during processing ${ }^{86,102,103}$ When $\alpha$-amylase was encapsulated, it is possible to observe an increase in the weight loss as a result of the enzyme activity. With 5\% of the enzyme encapsulated, almost all starch was hydrolyzed in the first week. These results indicate that the enzyme did not lose its activity during the preparation of the capsules, revealing a nondenaturing effect of the encapsulation technique on the enzyme activity.

The degradation effect of the encapsulated enzyme on the surface of the material can be observed in the SEM micrographs (Figure 12.5), where a highly porous structure is visible. This demonstrates that the enzyme was able to degrade the starch inside the matrix and diffuse from the bulk to the surface to carry out further starch hydrolysis. Furthermore, the encapsulation method seems to be adequate for controlling the degradability of starch-based biomaterials, since the enzyme possesses some degree of mobility, which is important for the degradation of insoluble substrates.

This method can, for instance, be used to incorporate a proper amount of $\alpha$-amylase in starchbased bone screws, fixation plates, or scaffolds in order to tailor their degradation profile.

Other enzyme immobilization techniques may be used to achieve biomaterials with enzymatically controlled degradation (please see Chapter 17 by Costa et al. in this book). An interesting approach is the incorporation of $\alpha$-amylase during the formation of calcium phosphate (Ca-P) coatings on starch polymeric blends with the aim of tailoring their degradation rate (please see Chapter 14 by Leonor et al. in this book). It was shown that, using a biomimetic ("nature-inspired") methodology to produce Ca-P coatings on the surface of biodegradable polymers, it is possible to incorporate enzymes without having loss of enzyme activity and at the same time tailor the properties of the coatings (composition, morphology, crystallinity, stability, etc.). 

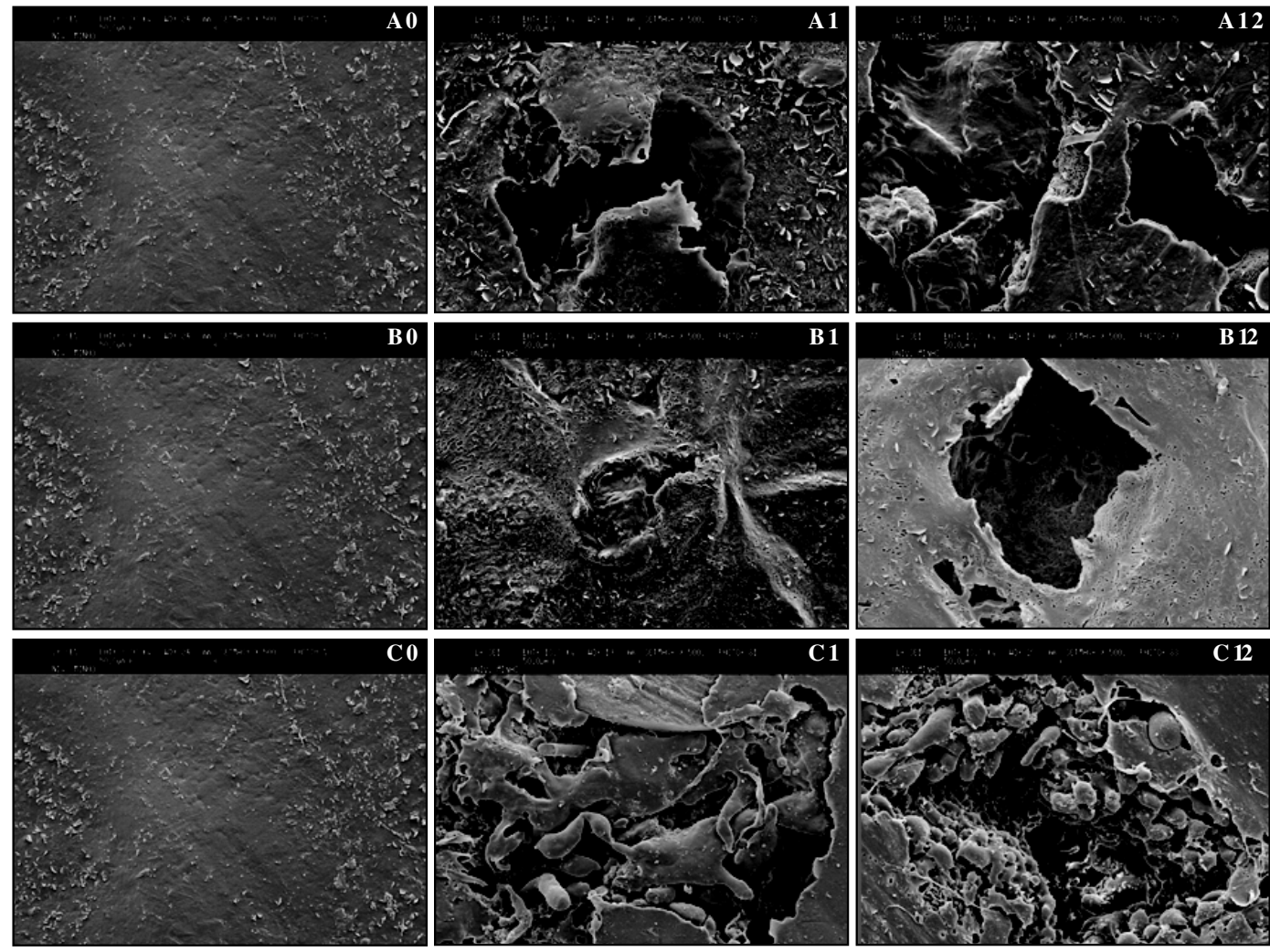

FIGURE 12.5 SEM micrographs of the surface of SPCL discs at different stages $(0,1$, and 12 weeks) of degradation $\left(\mathrm{pH} 5.5,37^{\circ} \mathrm{C}\right.$ ). Magnification $\times 500$. (A) Control sample; (B) sample with $\alpha$-amylase encapsulated $(0.5 \%)$; (C) sample with $\alpha$-amylase encapsulated (5\%).

\subsection{CONCLUDING REMARKS}

Most of the strategies developed to achieve biomaterials with controlled degradation rates have been based on molecular design principles such as the introduction of hydrolysable bonds into polymer backbones, copolymerization and blending techniques, crosslinking, and surface modification methods, depending on the type of application. The development of polymeric systems with a degradation rate controlled by a certain stimulus may constitute, however, a very promising approach with an increasing number of applications in the near future.

For instance, our research group proposed a new strategy to control the degradation rate of polymeric biomaterials by incorporating polymer-degrading enzymes on the biomaterials using different immobilization methods. The inclusion of highly sensitive molecules, such as enzymes, into polymeric biomaterials depends very much on the conditions used during the processing of each material, which are normally not "friendly" (high temperatures and shear rates, organic and acid solvents). This limitation may be overcome by the progress made in protein and genetic engineering fields, where enzyme activities (thermal and $\mathrm{pH}$ stabilities, substrate specificity) can be redesigned and tailored to have specific properties. This opens new possibilities of incorporating different biocatalysts during the processing of biomaterials that will then control their degradation profile, allowing for novel and challenging biomedical applications. 


\section{ACKNOWLEDGMENTS}

H. S. Azevedo thanks the Portuguese Foundation for Science and Technology for providing her a postdoctoral scholarship (SFRH/BPD/5744/2001). This work was partially supported by FCT Foundation for Science and Technology, through funds from the POCTI and/or FEDER programs.

\section{REFERENCES}

1. Cascone, M.G. et al., Bioartificial polymeric materials based on polysaccharides, J. Biomater. Sci. Polym. Ed., 12, 267, 2001.

2. Timmins, M.R., Lenz, R.W., and Fuller, R.C., Heterogeneous kinetics of the enzymatic degradation of poly( $\beta$-hydroxyalkanoates), Polymer, 28, 551, 1997.

3. Ratner, B.D. et al., Biomaterials Science. An Introduction to Materials in Medicine, Academic Press, San Diego, 1996, chap. 1.3, 2.3, 2.5, 2.7.

4. Shalaby, W.S.W. and Park, K., Chemical modification of proteins and polysaccharides and its effect on enzyme-catalyzed degradation, in Biomedical Polymers. Designed-to-Degrade Systems, Shalaby, S.W., Ed., Hanser Publishers, Munich, 1994, chap. 9.

5. Tangpasuthadol, V., Pendharkar, S., and Kohn, J., Hydrolytic degradation of tyrosine polycarbonates, a class of new biomaterials. Part I: study of the model compounds, Biomaterials, 21, 2371, 2000.

6. Göpferich, A., Mechanisms of polymer degradation and erosion, Biomaterials, 17, 103, 1996.

7. Hanes, J., Chiba, M., and Langer, R., Degradation of porous poly(anhydride-co-imide) microspeheres and implications for controlled macromolecule delivery, Biomaterials, 19, 163, 1998.

8. Mainil-Varlet, P., Curtis, R., and Gogolewski, S., Effect of in vivo and in vitro degradation on molecular and mechanical properties of various low-molecular-weight polylactides, J. Biomed. Mater. Res., 36, 360, 1997.

9. Agrawal, C.M. and Athanasiou, K.A., Technique to control pH in vicinity of biodegrading PLA-PGA implants, J. Biomed. Mater. Res. (Appl. Biomater.), 38, 105, 1997.

10. Malin, M. et al., Biodegradable lactone copolymers. II. Hydrolytic study of $\varepsilon$-caprolactone and lactide copolymers, J. Appl. Polym. Sci., 59, 1289, 1996.

11. Tracy, M.A. et al., Factors affecting the degradation rate of poly(lactide-co-glycolide) microspheres in vivo and in vitro, Biomaterials, 20, 1057, 1999.

12. Birnbaum, D.T. and Brannon-Peppas, L., Molecular weight distribution during degradation and release of PLGA nanoparticles containing epirubicin HCl, J. Biomater. Sci. Polym. Ed., 14, 87, 2003.

13. Dunn, A.S. et al., The influence of polymer blend composition on the degradation of polymer/hydroxyapatite biomaterials, J. Mater. Sci. Mater. Med., 12, 673, 2001.

14. Lu, L., Garcia, C.A., and Mikos, A.G., In vitro degradation of thin poly(DL-lactic-co-glycolic acid) films, J. Biomed. Mater. Res., 46, 236, 1999.

15. Zong, X.-H. et al., Structure and morphology changes in absorbable poly(glycolide) and poly(glycolide-co-lactide) during in vitro degradation, Macromolecules, 32, 8107, 1999.

16. Li, S., Hydrolytic degradation characteristics of aliphatic polyesters derived from lactic and glycolic acids, J. Biomed. Mater. Res. (Appl. Biomater.), 48, 342, 1999.

17. Williams, D.F. and Zhong, S.P., Biodeterioration/biodegradation of polymeric medical devices in situ, Int. Biodeter. Biodegrad., 95, 1994.

18. Coleman, J.W., Nitric oxide in immunity inflammation, Int. Immunopharm., 1, 1397, 2001.

19. Labow, R.S. et al., The effect of oxidation on the enzyme-catalyzed hydrolytic biodegradation of poly(urethan)s, J. Biomater. Sci. Polym. Ed., 13, 651, 2002.

20. Lee, K.-H. and Chu, C.C., The role of superoxide ions in the degradation of synthetic absorbable sutures, J. Biomed. Mater. Res., 49, 25, 2000.

21. Santerre, J.P. et al., Biodegradation evaluation and polyester-urethanes with oxidative and hydrolytic enzymes, J. Biomed. Mater. Res., 28, 1187, 1994.

22. Labow, R.S., Meek, E., and Santerre, P., The biodegradation of poly(urethane)s by the esterolytic activity of serine proteases and oxidative enzyme systems, J. Biomater. Sci. Polym. Ed., 10, 699, 1999. 
23. Bruining, M.J. et al., New biodegradable networks of poly( $N$-vinylpyrrolidinine $)$ designed for controlled nonburst degradation in the vitreous body, J. Biomed. Mater. Res., 47, 189, 1999.

24. Hasirci, V. et al., Versatility of biodegradable polymers: degradability and in vivo application, $J$. Biotechnol., 86, 135, 2001.

25. Rahmouni, M. et al., Enzymatic degradation of cross-linked high amylose starch tablets and its effect on in vitro release of sodium diclofenac, Eur. J. Pharm. Biopharm., 51, 191, 2001.

26. Tang, Y.W., Labow, R.S., and Santerre, J.P., Enzyme induced of polycarbonate-polyurethanes: dose dependence of cholesterol esterase, Biomaterials, 24, 2003, 2003.

27. Nordtveit, R.J., Vårum, K.M., and Smidsrød, O., Degradation of partially $N$-acetylated chitosans with hen egg white and human lysozyme, Carbohydr. Polym., 29, 163, 1996.

28. Tomihata, K. and Ikada, Y., In vitro and in vivo degradation of films of chitin and its deacetylated derivatives, Biomaterials, 18, 567, 1997.

29. Mi, F.-L. et al., In vitro evaluation of a chitosan membrane cross-linked with genipin, J. Biomater. Sci. Polym. Ed., 12, 835, 2001.

30. Tang, Y.W., Labow, R.S., and Santerre, J.P., Enzyme-induced biodegradation of polycarbonate-polyurethanes: dependence on hard-segment concentration, J. Biomed. Mater. Res., 56, 516, 2001.

31. Tang, Y.W., Labow, R.S., and Santerre, J.P., Enzyme-induced biodegradation of polycarbonate-polyurethanes: dependence on hard-segment chemistry, J. Biomed. Mater. Res., 57, 597, 2001.

32. Santerre, J.P. and Labow, R.S., The effect of hard segment size on the hydrolytic stability of polyetherurea-urethanes when exposed to cholesterol esterase, J. Biomed. Mater. Res., 36, 223, 1997.

33. Griffiths, M.M., Langone, J.J., and Lightfoote, M.M., Biomaterials and granulomas, Methods: A Comparison to Methods in Enzymol., 9, 295, 1996.

34. Jahangir, J. et al., The influence of protein adsorption and surface modifying macromolecules on the hydrolytic degradation of a poly(ether-urethane) by cholesterol esterase, Biomaterials, 24, 3969, 2002.

35. Price, N.C and Stevens, L., Fundamentals of Enzymology. The Cell and Molecular Biology of Catalytic Proteins, 3rd ed., Oxford University Press, Oxford, 1999, chap. 8, 10.

36. Junge, W. et al., Evaluation of a new assay for pancreatic amylase: performance characteristics and estimation of reference intervals, Clin. Biochem., 22, 109, 1989.

37. Chawla, J.S. and Amiji, M.M., Biodegradable poly( $\varepsilon$-caprolactone) nanoparticles for tumor-targeted delivery tamoxifen, Int. J. Pharm., 249, 127, 2002.

38. Garnero, P. and Delmas, P.D., Assessment of the serum levels of bone alkaline phosphatase with new immunoradiometric assay in patients with metabolic bone disease, J. Clin. Endocrinol. Metab., 77, 1046, 1993.

39. Rogers, S.W. and Rechsteiner, M., Degradation of structurally characterized proteins injected into HeLa cells, J. Biol. Chem., 263, 19833, 1988.

40. Tietz, N.W. and Shuey, D.F., Lipase in serum - the elusive enzyme: an overview, Clin. Chem., 39/5, 746, 1993.

41. Cassim, B., Mody, G., and Bhoola, K.D., Kallikrein cascade and cytokines in inflamed joints, Pharmacol. Therap., 94, 1, 2002.

42. Duguay, D.G. et al., Development of a mathematical model describing the enzymatic degradation of biomedical polyurethanes. 1. Background, rationale and model formulation, Polym. Degrad. Stabil., 47, 229, 1995.

43. Labow, R.S., Erfle, D.J., and Santerre, J.P., Neutrophil-mediated degradation of segmented polyurethanes, Biomaterials, 16, 51, 1995.

44. Erfle, D.J., Santerre, J.P., and Labow, R.S., Lysosomal enzyme release from human neutrophils adherent to foreign material surfaces: Enhanced release of elastase activity, Cardiovasc. Pathol., 6, 333, 1997.

45. Retrieved from http://www.expasy.ch

46. Zhong, S.P. et al., Biodegradation of hyaluronic acid derivatives by hyaluronidase, Biomaterials, 15 , 359, 1994.

47. Luo, Y., Kirker, K.R., and Prestwich, G.D., Cross-linked hyaluronic acid hydrogel films: news biomaterials for drug delivery, J. Control. Release, 69, 169, 2000.

48. Dumoulin, Y., Cartilier, L.H., and Mateescu, M.A., Cross-linked amylose tablets containing $\alpha$-amylase: an enzymatically-controlled drug release system, J. Control. Release, 60, 161, 1999. 
49. Labow, R.S., Meek, E., and Santerre, J.P., Differential synthesis of cholesterol esterase by monocytederived macrophages cultured on poly(ether or ester)-based poly(urethane)s, J. Biomed. Mater. Res., 39, 469, 1998.

50. Wang, G.B., Labow, R.S., and Santerre, J.P., Biodegradation of a poly(ester-urea-urethane) by cholesterol esterase: Isolation and identification of principal biodegradation products, J. Biomed. Mater. Res., 36, 407, 1997.

51. Tang, Y.W. et al., Use of surface-modifying macromolecules to enhance the biostability of segmented polyurethanes, J. Biomed. Mater. Res., 35, 371, 1997.

52. Tang, Y.W. et al., Application of macromolecular additives to reduce the hydrolytic degradation of polyurethanes by lysosomal enzymes, Biomaterials, 18, 37, 1997.

53. Labow, R.S. et al., Human macrophage-mediated biodegradation of polyurethanes: assessment of candidate activities, Biomaterials, 23, 2003, 2003.

54. Labow, R.S. et al., Elastase-induced hydrolysis of synthetic solid substrates: poly(ester-urea-urethane) and poly(ether-urea-urethane), Biomaterials, 17, 2381, 1996.

55. Woo, G.L.Y., Mittelman, M.W., and Santerre, J.P., Synthesis and characterization of a novel biodegradable antimicrobial polymer, Biomaterials, 21, 1235, 2000.

56. Tang, Y.W., Labow, R.S., and Santerre, J.P., Isolation of methylene dianiline and aqueous-soluble biodegradation products from polycarbonate-polyurethanes, Biomaterials, 14, 2805, 2003.

57. Elliot, S.L. et al., Identification of biodegradation products formed by L-phenylalanine based segmented polyurethaneureas, J. Biomater. Sci. Polym. Ed., 13, 691, 2002.

58. Tang, Y.W. et al., Influence of surface morphology and chemistry on the enzyme catalysed biodegradation of polycarbonate-urethanes, J. Biomater. Sci. Polym. Ed., 13, 463, 2002.

59. Matheson, L.A., Labow, R.S., and Santerre, J.P., Biodegradation of polycarbonate-based polyurethanes by the human monocyte-derived macrophage and U937 cell systems, J. Biomed. Mater. Res., 61, 505, 2002.

60. Labow, R.S., Meek, E., and Santerre, J.P., Model systems to assess the destructive potential neutrophils and monocyte-derived macrophages during the acute and chronic phases inflammation, J. Biomed. Mater. Res., 54, 189, 2001.

61. Labow, R.S., Meek, E., and Santerre, J.P., Hydrolytic degradation of poly(carbonate)-urethanes by monocyte-derived macrophages, Biomaterials, 22, 3025, 2001.

62. Tsuji, H. and Muramatsu, H., Blends of aliphatic polyesters: V Non-enzymatic and enzymatic hydrolysis of blends from hydrophobic poly(L-lactide) and hydrophilic poly(vinyl alcohol), Polym. Degrad. Stabil., 71, 403, 2001.

63. Liu, L. et al., Selective enzymatic degradations of poly(L-lactide) and poly(ع-caprolactone) blend films, Biomacromolecules, 1, 350, 2000.

64. Li, S. and McCarthy, S., Influence of crystallinity and stereochemistry on the enzymatic degradation of poly(lactide)s, Macromolecules, 32, 4454, 1999.

65. Schakenraad, J.M. et al., Enzymatic activity toward poly(L-lactic acid) implants, J. Biomed. Mater. Res., 24, 529, 1990.

66. Gan, Z. et al., Enzymatic degradation of poly(E-caprolactone) film in phosphate buffer containing lipases, Polym. Degrad. Stabil., 56, 209, 1997.

67. Darwis, D. et al., Enzymatic degradation of radiation crosslinked poly(ع-caprolactone), Polym. Degrad. Stabil., 62, 259, 1998.

68. Renier, M.L. and Kohn, D.H., Development and characterization of a biodegradable polyphosphate, J. Biomed. Mater. Res., 34, 95, 1997.

69. Chaubal, M.V. et al., In vitro and in vivo degradation studies of a novel linear copolymer of lactide and ethylphosphate, J. Biomater. Sci. Polym. Ed., 14, 45, 2003.

70. Jiang, H.L. et al., In vivo degradation and biocompatability of a new class of alternate poly(esteranhydrides) based on aliphatic and aromatic diacids, J. Biomater. Sci. Polym. Ed., 12, 1281, 2001.

71. Hooper, K.A., Macon, N.D., and Kohn, J., Comparative histological evaluation of new tyrosine-derived polymers and poly(L-lactic acid) as a function of polymer degradation, J. Biomed. Mater. Res., 41, 443, 1998.

72. Ambrosio, A.M.A. et al., Degradable polyphosphazene/poly( $\alpha$-hydroxyester) blends: degradation studies, Biomaterials, 23, 1667, 2002. 
73. Zhang, J.-Y. et al., Synthesis, biodegradability, and biocompatibility of lysine diisocyanate-glucose polymers, Tissue Eng., 8, 771, 2002.

74. Agrawal, C.M. et al., Effects of fluid flow on the in vitro degradation kinetics of biodegradable scaffolds for tissue engineering, Biomaterials, 21, 2443, 2000.

75. ISO TR 10993-9, Biological evaluation of medical devices - Part 9: Degradation of materials related with biological testing, 1994.

76. ISO 10993-13, Biological evaluation of medical devices — Part 13: Identification and quantification of degradation products from polymers, 1997.

77. Yashin, M. and Tighe, B.J., Strategies for the design of biodegradable polymers systems: manipulation of polyhydroxybutyrate-based materials, Plast. Rub. Compos. Pro. Appl., 19, 15, 1993.

78. Marois, Y. et al., Mechanism and rate of degradation of polyhydroxyoctanoate films in aqueous media: a long term in vitro study, J. Biomed. Mater. Res., 49, 216, 2000.

79. Göpferich, A., Erosion of composite polymer matrices, Biomaterials, 18, 397, 1997.

80. Burkoth, A.K., Burdick, J., and Anseth, K.S., Surface and bulk modifications to photocrosslinked polyanhydrides to control degradation behavior, J. Biomed. Mater. Res., 51, 352, 2000.

81. Griesser, H.J., Degradation of polyurethanes in biomedical applications - a review, Polym. Degrad. Stabil., 33, 329, 1991.

82. Tamada, J.A. and Langer, R., Erosion kinetics of hydrolytically degradable polymers, Proc. Natl. Acad. Sci. U.S.A., 90, 552, 1993.

83. Agrawal, C.M., In vitro testing of polymeric scaffolds, in Polymer Based Systems on Tissue Engineering, Replacement and Regeneration, Reis, R.L. and Cohn, D., Eds., Kluwer Academic Publishers, Dordrecht, 2002, pp. 113-123.

84. Hubbell, J.A., Synthetic biodegradable polymers for tissue engineering and drug delivery, Curr. Opin. Solid State Mater. Sci., 3, 246, 1998.

85. Yaszemski, M.J. et al., In vitro degradation of a poly(propylene fumarate)-based composite material, Biomaterials, 17, 2127, 1996.

86. Azevedo, H.S., Gama, F.M., and Reis, R.L., In vitro assessment of the enzymatic degradation of several starch based biomaterials, Biomacromolecules, 4, 1703, 2003.

87. Langer, R., Biomaterials and biomedical engineering, Chem. Eng. Sci., 50, 4109, 1995.

88. Tangpasuthadol, V. et al., Hydrolytic degradation of tyrosine polycarbonates, a class of new biomaterials. Part II: 3-yr study of polymeric devices, Biomaterials, 21, 2379, 2000.

89. Hubbell, J.A., Biomaterials in tissue engineering, Bio/Technol., 13, 565, 1995.

90. Skarja, G.A. and Woodhouse, K.A., In vitro degradation and erosion of degradable, segmented polyurethanes containing an amino acid-based chain extender, J. Biomater. Sci. Polym. Ed., 12, 851, 2001.

91. Bruin, P. et al., Biodegradable lysine diisocyanate-based poly(glycolide-co-epsilon-caprolactone)urethane network in artificial skin, Biomaterials, 11, 291, 1990.

92. West, J.L. and Hubbell, J.A., Polymeric biomaterials with degradation sites for proteases involved in cell migration, Macromolecules, 32, 241, 1999.

93. Kamimura, W., Ooya, T., and Yui, N., Transience in polyion complexation between nicotinamidemodified dextran and carboxymethyl dextran during enzymatic degradation of dextran, J. Biomater. Sci. Polym. Ed., 12, 1109, 2001.

94. Reis, R.L. and Cunha, A.M., Characterisation of two biodegradable polymers of potential application within the biomaterials field, J. Mater. Sci. Mater. Med., 6, 786, 1995.

95. Pereira, C.S. et al., New starch-based thermoplastic hydrogels for use as bone cements or drug delivery carriers, J. Mater. Sci. Mater. Med., 9, 825, 1998.

96. Malafaya, P.B. et al., Porous starch-based drug delivery systems processed by a microwave route, $J$. Biomater. Sci. Polym. Ed., 12, 1227, 2001.

97. Elvira, C. et al., Starch based biodegradable hydrogels with potential biomedical applications as drug delivery systems, Biomaterials, 23, 1955, 2002.

98. Espigares, I. et al., New partially degradable and bioactive acrylic bone cements based on starch blends and ceramic fillers, Biomaterials, 23, 1883, 2002.

99. Gomes, M.E. et al., A new approach based on injection moulding to produce biodegradable starchbased polymeric scaffolds: morphology, mechanical and degradation behaviour, Biomaterials, 22, 883, 2001. 
100. Elvira, C. et al., Plasma- and chemical induced graft polymerisation on the surface of starch-based biomaterials aimed at improving cell adhesion and proliferation, J. Mater. Sci. Mater. Med., 14, 187, 2003.

101. Demirgöz, D. et al., Chemical modification of starch based biodegradable polymeric blends: effects on water uptake, degradation behaviour and mechanical properties, Polym. Degrad. Stabil., 70, 161, 2000.

102. Reis, R.L. et al., Processing and in vitro degradation of starch/EVOH thermoplastic blends, Polym. Int., 43, 347, 1997.

103. Leonor, I.B. et al., Novel starch thermoplastic/Bioglass ${ }^{\circledR}$ composites: mechanical properties, degradation behavior and in-vitro bioactivity, J. Mater. Sci. Mater. Med., 13, 939, 2002.

104. Reis, R.L. and Cunha, A.M., Starch and starch based thermoplastic, in Encyclopedia of Materials Science and Technology (11 volumes), Volume on Biological and Biomimetic Materials, Jurgen, K.H., Buschow, R., Cahn, W., Flemings, M.C., Ilschner, B., Kramer, E.J., and Mahajan, S., Eds., PergamonElsevier Science, Amsterdam, 2001, pp. 8810-8816.

105. van Ingen, H.E. and Sanders, G.T.B., Clinical evaluation of a pancreatic lipase mass concentration assay, Clin. Chem., 38, 2310, 1992.

106. Pawlak, A. and Mucha, M., Thermogravimetric and FTIR studies of chitosan blends, Thermochim. Acta, 396, 153, 2003.

107. Walsh, D., Furuzono, T., and Tanaka, J., Preparation of porous composite materials by in situ polymerization of porous apatite containing $\varepsilon$-caprolactone or methacrylate, Biomaterials, 22, 1205, 2001. 
